\title{
A Clinical Triad of Digital Clubbing, "Arthritis" and Ossifying Periostitis in a Man: Case Report
}

\author{
Chun-Ruh Ng*, Yet-Lin Loh \\ Department of Internal Medicine, Hospital Sultan Ismail, Johor, Malaysia \\ Email: *angiepaeds@gmail.com
}

How to cite this paper: Ng, C.-R. and Loh, Y.-L. (2019) A Clinical Triad of Digital Clubbing, "Arthritis" and Ossifying Periostitis in a Man: Case Report. Open Access Library Journal, 6: e5101.

https://doi.org/10.4236/oalib.1105101

Received: December 7, 2018

Accepted: January 7, 2019

Published: January 10, 2019

Copyright $\odot 2019$ by author(s) and Open Access Library Inc.

This work is licensed under the Creative Commons Attribution International License (CC BY 4.0).

http://creativecommons.org/licenses/by/4.0/

(c) (i) Open Access

\begin{abstract}
A 49 year old gentleman presented with intermittent bilateral knee swelling for the past 37 years and was eventually diagnosed as primary hypertrophic osteoarthropathy after secondary forms were excluded. This case illustrates that the disease can present during childhood with an insidious onset and progressively become more severe and that is when medical attention is sought. Furthermore, the patient did not voluntarily report his skin changes as he considered the slow progressive changes as normal. We report a case of primary hypertrophic osteoarthropathy, its clinical presentation, imaging findings and therapeutic treatment. It is a rare differential diagnosis for chronic joint pain and swelling.
\end{abstract}

\section{Subject Areas}

Anaesthesiology \& Pain Management, Internal Medicine, Orthopedics, Radiology \& Medical Imaging, Rheumatology

\section{Keywords}

Hypertrophic Osteoarthropathy, Pachydermoperiostosis, Cutis Verticis Gyrata, Periosteal Reaction, Clubbing

\section{Introduction}

Primary or idiopathic hypertrophic osteoarthropathy (also called pachydermoperiostosis and Touraine-Solente - Gole syndrome) is a condition characterized by digital clubbing of both hands and feet, extremity enlargement secondary to bone and periarticular tissue proliferation, joint pain and edema, bilateral eyelid ptosis and thickened skin. The genetic abnormality involves a mutation in the HPGD gene that encodes 15 hydroxyprostaglandin dehydrogenase which is the primary enzyme responsible for prostaglandin degradation as described by Up- 
pal et al. [1]. The second gene that had been reported in Japanese, Chinese and Korean patients is the SLCO2A1 gene. The primary form is not associated with any other medical disorders whereas the secondary form occurs in patients with underlying lung pathology, cardiac, hepatic and gastrointestinal disease. Since prostaglandin is likely to be involved in periosteal bone formation and acroosteolysis this explains why non-steroidal anti-inflammatory drugs and steroids are useful in alleviating arthritis [2].

\section{Case Report}

A 49 year old gentleman presented to our department 6 years ago with hypertrophic osteoarthropathy. His medical history began at the age of 12 when he complained of intermittent bilateral knee swelling and pain. It was insidious in onset and gradually worsening. He had multiple right knee aspirations and left knee arthrotomy with biopsy done 12 years ago but results were all inconclusive. He also complained of right wrist pain and swelling. He denied alopecia, oral ulcer, photosensitivity or fever.

The patient had no cardiovascular, gastrointestinal or respiratory symptoms.

There was no family history of similar condition.

Clinical examination noted presence of drooping of both eyelids and thickening of the facial skin and scalp. He had greasy and coarse skin with deeply furrowed forehead skin (Figure 1). His scalp showed a cerebriform appearance with accentuating folds and furrows (cutis verticis gyrata) [3], (Figure 2). There was no cyanosis, jaundice, palmar erythema or prognathism. His cardiovascular, respiratory, abdomen and central nervous system examinations were normal.

The musculoskeletal examination showed presence of digital clubbing of both hands and feet with diffuse swelling of both knees, right wrist and both ankles (Figures 3-6).

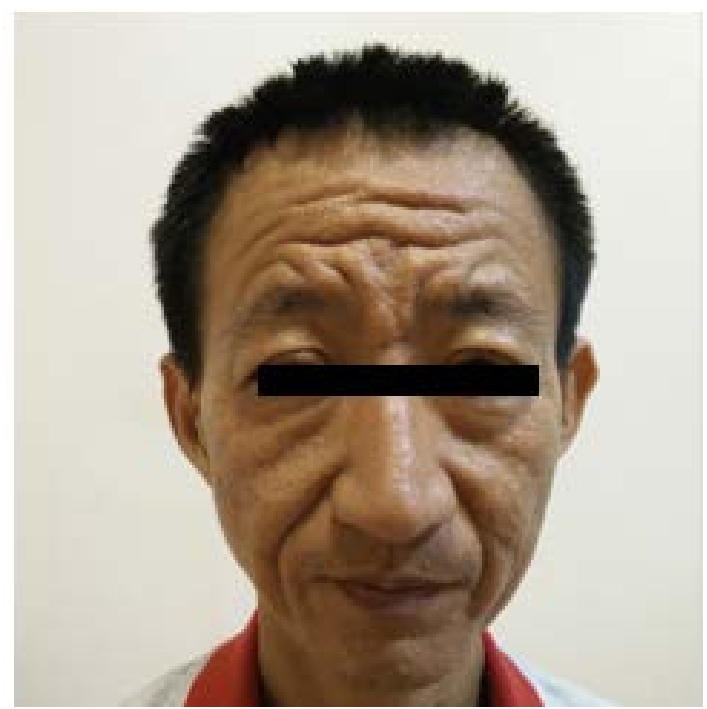

Figure 1. Shows bilateral ptosis, thickening of facial skin and deeply furrowed forehead. 


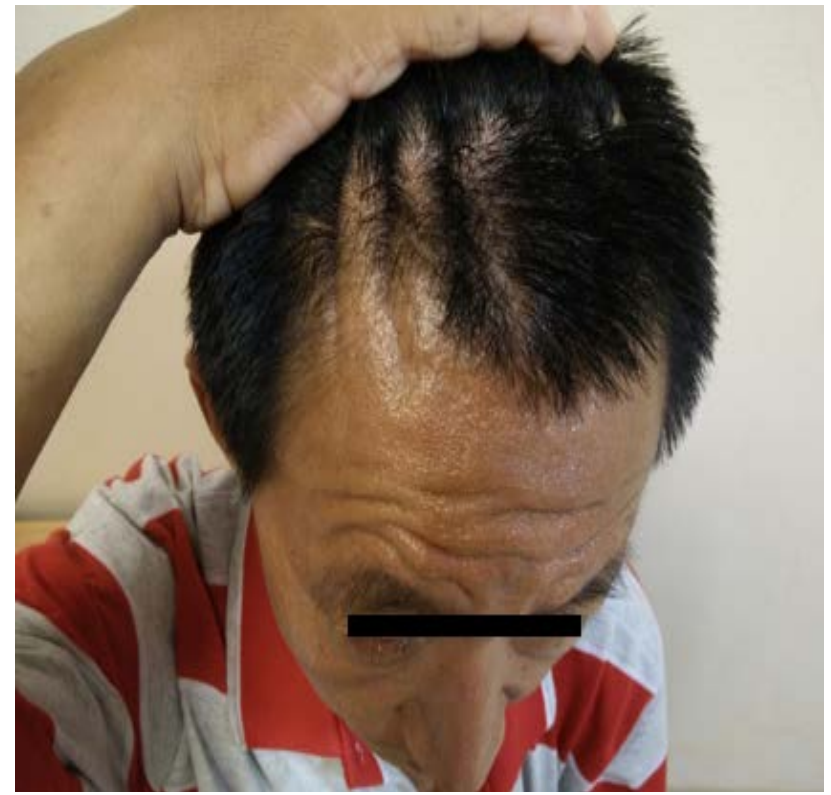

Figure 2. Illustrates cutis verticis gyrata.

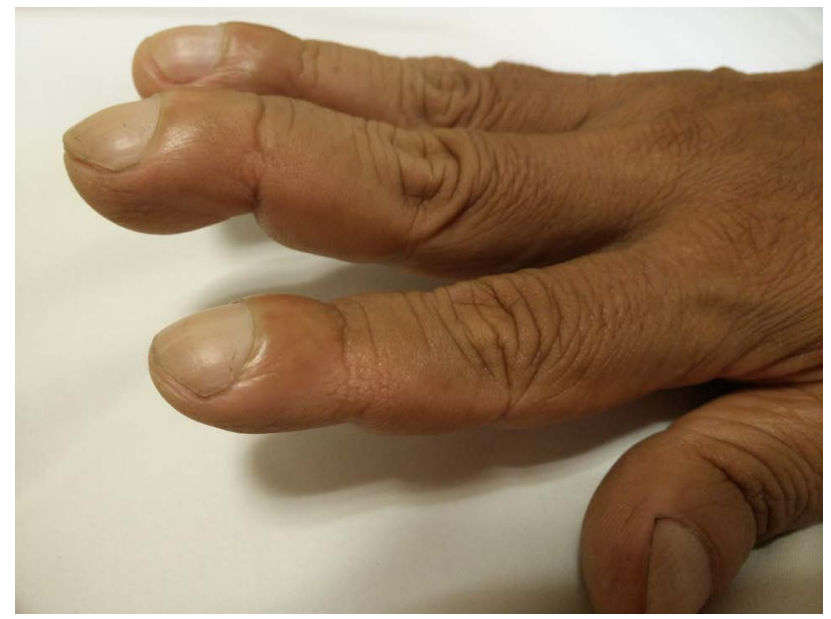

Figure 3. Shows digital clubbing.

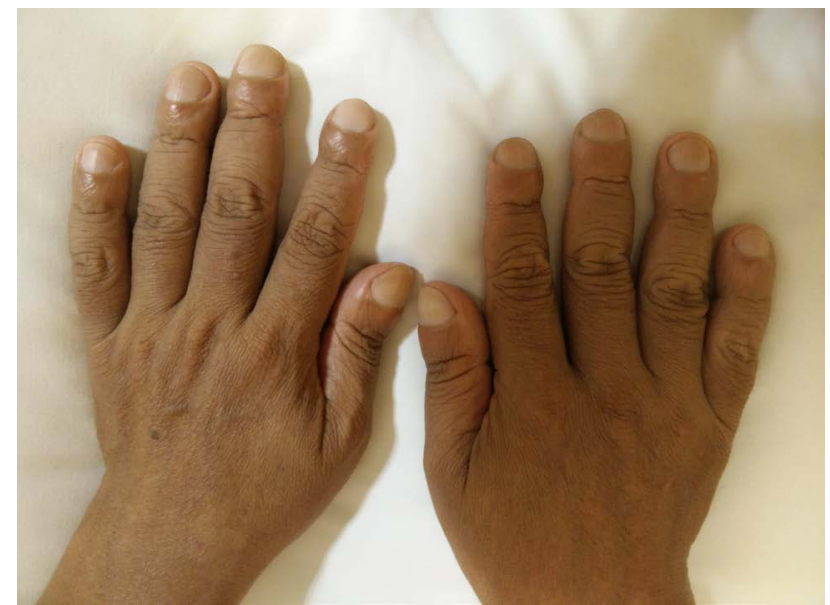

Figure 4. Shows swelling of right wrist. 


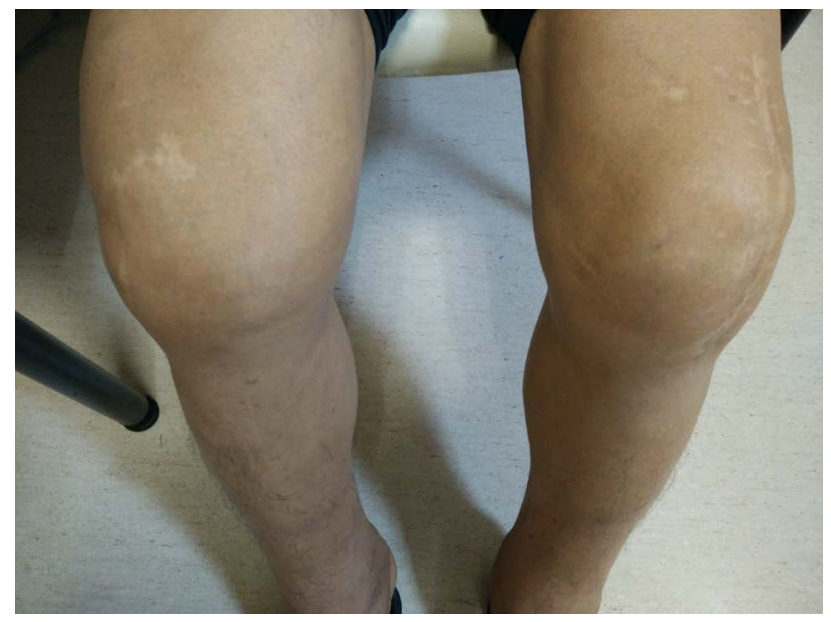

Figure 5. Shows swelling of both knees.

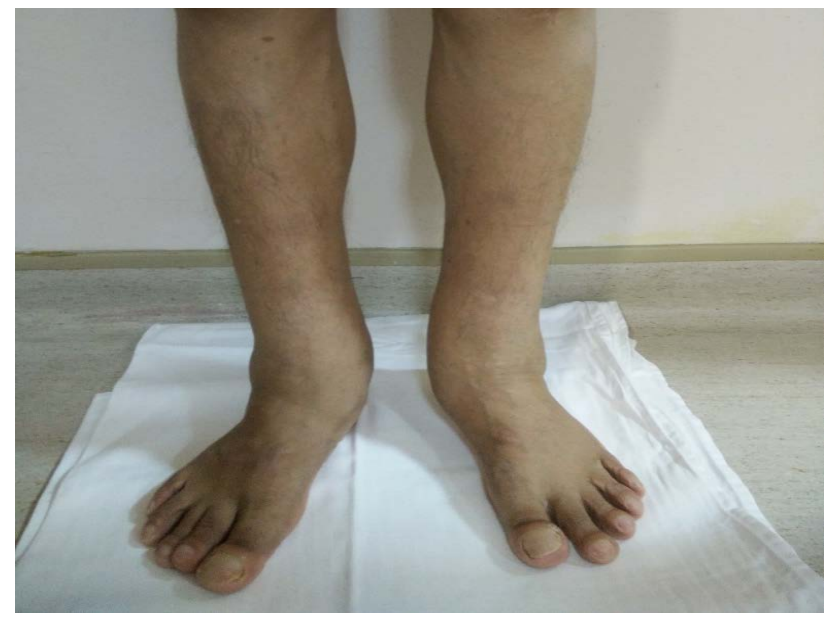

Figure 6. Illustrates bilateral ankles swelling and digital clubbing.

$\mathrm{X}$ ray of the hands showed prominence of soft tissue and enlargement of the proximal, middle and distal phalanges with cortical thickening (Figure 7). There was also periosteal reaction with bone formation affecting his long bones (Figure 8).

Laboratory analysis showed a normal full blood count with a haemoglobin of $13.9 \mathrm{~g} / \mathrm{dl}$, white blood cell count of 9,900 cells/ul of which $60 \%$ were neutrophils and platelet of 208,000/ul. The inflammatory markers erythrocyte sedimentation rate (ESR) and C-reactive protein (CRP) were $28 \mathrm{~mm} / \mathrm{h}$ and $2.7 \mathrm{mg} / \mathrm{L}$ respectively. His renal and liver function tests were normal. The rheumatoid factor and antinuclear antibody tests were negative. Chest $\mathrm{x}$ ray was normal. Clinical evaluation, laboratory investigation and imaging did not show presence of any condition that can be associated with hypertrophic osteoarthropathy in this patient. The patient was prescribed NSAIDS for his musculoskeletal pain of which he responded well.

The patient has been on our follow up for the last 6 years and so far there has been no development of other medical disorders. 


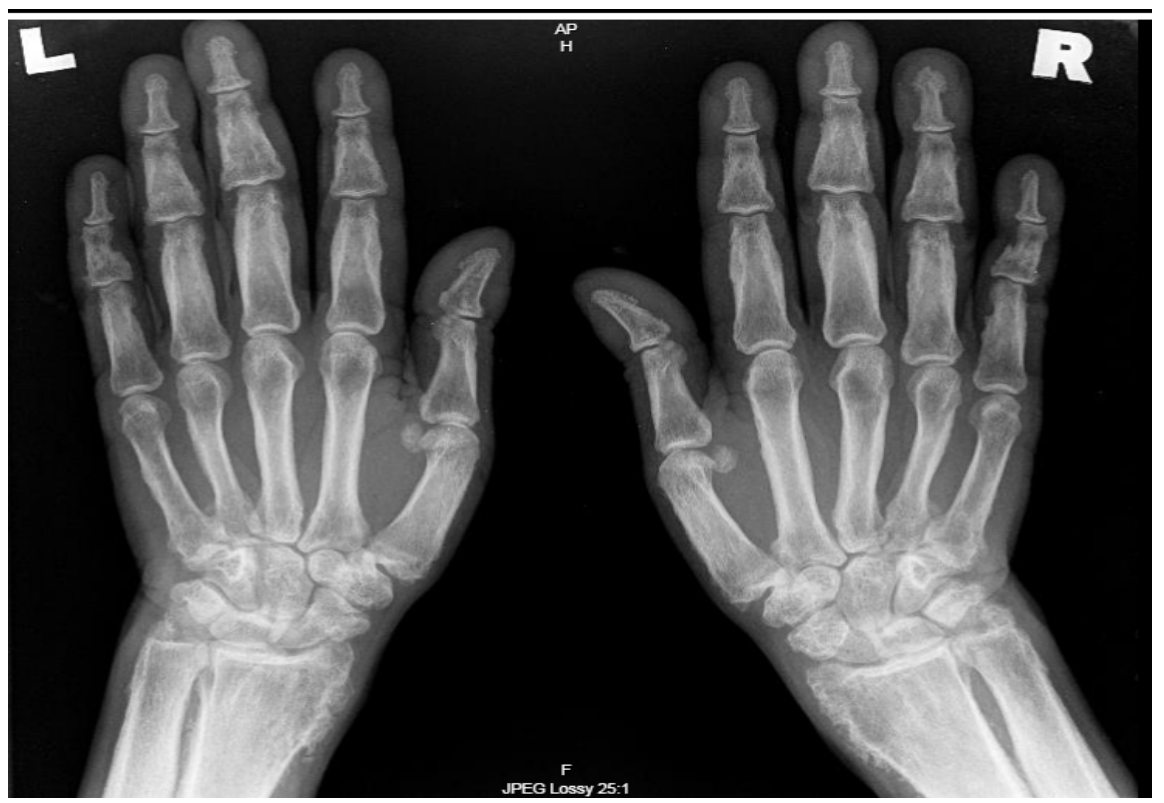

Figure 7. X ray of both hands shows cortical thickening and periostosis.

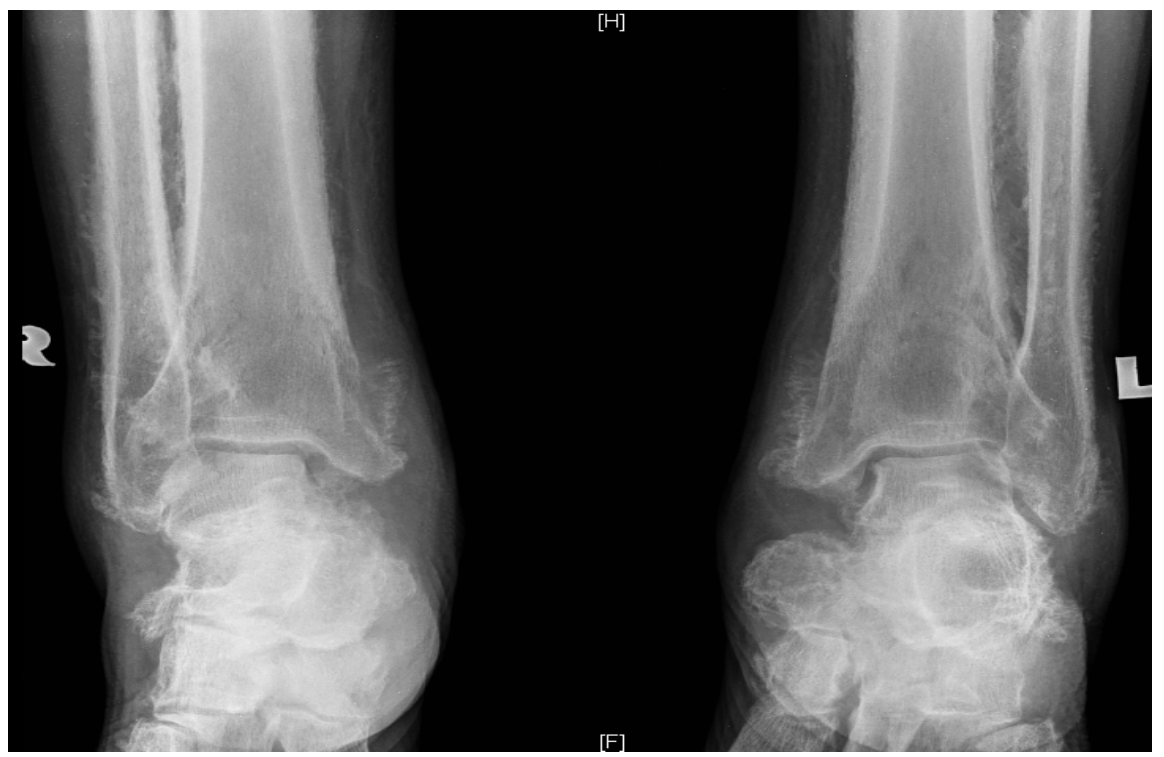

Figure 8. X ray of both legs shows cortical thickening with periosteal reaction with shaggy, ill-defined bony proliferation involving diaphysis, metaphysis and epiphysis.

\section{Discussion}

Hypertrophic osteoarthropathy (HOA) is a syndrome of digital clubbing, ossifying periostitis and "arthritis" and this clinical triad has been recognised since the late 1800s [4]. The disease is classified either as primary (hereditary or idiopathic) or secondary. The three recognised forms of primary osteoarthropathy are: 1) complete (pachydermia, digital clubbing and periostosis), 2) incomplete (no pachydermia) and 3) fruste form (prominent pachydermia with few skeletal manisfestations) as proposed by Touraine et al. [5] [6]. Based on clinico-radiological findings we made the diagnosis of complete form of primary hypertrophy os- 
teoarthropathy after excluding associated diseases and other differential diagnosis.

Primary hypertrophic osteoarthropathy represents 3\% of all cases of hypertrophic osteoarthropathy. Its prevalence in the general population is not exactly known. Typically men are more commonly affected than women with a ratio of 9:1 [7]. It is a rare genetic disorder with autosomal dominant transmission. Autosomal recessive transmission and $\mathrm{X}$-linked mutations have been also described [8]. The clinical condition typically begins in adolescence evolving insidiously for 5 to 10 years and then usually remains unchanged thereafter.

Clinical manifestations are variable as three forms of primary HOA have been described. Ocular manifestation in our patient are mainly related to ptosis and chronic tarsitis. The eyelid thickening and subsequent development of ptosis is due to sebaceous gland hyperplasia and dermal mucin deposition in the eyelid [9].

The thickening of the facial skin and scalp resulting in leonine facies is caused by dysregulation of mesenchymal cell [10]. Other features are acne, eczema, seborrhea, and palmoplantar hyperhidrosis. The skin of the hands and feet are also thickened but usually not folded.

Rheumatological signs include joint effusion (41\% of cases) which often affect the knees with excessive synovial fluid. The articular surfaces are spared but intermittent swelling of the joints is common and often cause moderate pain. The joint effusions are more likely due to sympathetic reaction to nearby periostosis.

The characteristic radiological features are bilateral and symmetrical cortical thickening and long bone periostitis. Periosteal reaction is irregular and involves the diaphysis and often extends to the epiphysis. There is preservation of joint space with absence of erosions or periarticular osteopenia [11].

This patient initially presented with bilateral knee swelling at the age of 12 and the diagnosis of primary hypertrophic osteoarthropathy was made three decades after the onset of symptoms.

He requires regular follow up as some patients had been reported to develop diseases such as crohn's disease and myelofibrosis [12] [13].

\section{Conclusion}

The diagnosis of primary hypertrophic osteoarthropathy requires awareness of the disease in view of its rarity and varied clinical findings. Majority of the patients require conservative management. Patients are reassured of the good prognosis of the musculoskeletal involvement. However they must also be informed the importance of ruling out associated disorders.

\section{Funding}

This case report has received no specific grant from any funding agency.

\section{Conflicts of Interest}

The authors have no conflict of interest to declare. 


\section{Consent}

Written informed consent was obtained from the patient for the publication of this case report and any accompanying images.

This case study was registered under the National Medical Research Registry of Malaysia in November 2018.

\section{References}

[1] Uppal, S., et al. (2008) Mutations in 15-Hydroxyprostaglandin Dehydrogenase Cause Primary Hypertrophic Osteoarthropathy. Nature Genetics, 40, 789-793. https://doi.org/10.1038/ng.153

[2] Gómez Rodríguez, N., Ibáñez Ruán, J. and González Pérez, M. (2009) Primary Hypertrophic Osteoarthropathy (Pachydermoperiostosis). Report of 2 Familial Cases and Literature Review. Reumatología Clínica, 5, 259-263. https://doi.org/10.1016/j.reuma.2009.01.007

[3] James, W., Berger, T. and Elston, D. (2005) Andrews' Diseases of the Skin: Clinical Dermatology. 10th Edition, Saunders, 572.

[4] Fauci, A.S., et al., Eds. (2008) Harrison's Principles of Internal Medicine. McGraw-Hill Medical, New York.

[5] Touraine, A., Solente, G. and Gole, L. (1935) Un syndrome osteodermopathique: La pachydermie plicaturee avec pachyperiostose des extremites. La Presse Médicale, 43, $1820-1824$.

[6] Karnan, S., Krishnamoorthy, V., Ethiraj, P. and Sathynathan, B.P. (2012) Touraine-Solente-Gole Syndrome. The Complete form Needs to Be Recognised. Indian Journal of Nuclear Medicine, 27, 201-204.

[7] Jajic, I. and Jajic, Z. (1992) Prevalence of Primary Hypertrophic Osteoarthropathy. Clinical and Experimental Rheumatology, 10, 73.

[8] Castori, M., et al. (2005) Pachydermoperiostosis: An Update. Clinical Genetics, 68, 477-486. https://doi.org/10.1111/j.1399-0004.2005.00533.x

[9] Offret, H., Venencie, P.Y., Fain, J., Quillard, J. and Badarani, N. (1996) Involvement of the Connective Tissue of the Eyelids in Pachydermoperiostosis. Journal Français D'Ophtalmologie, 19, 64-68. [Article in French].

[10] Kabashima, K., Sakabe, J., Yoshiki, R., Tabata, Y., Kohno, K. and Tokura, Y. (2010) Involvement of Wnt Signaling in Dermal Fibroblasts. The American Journal of Pathology, 176, 721-732. https://doi.org/10.2353/ajpath.2010.090454

[11] Bauer, J.S. (2008) Hypertrophic Osteoarthropathy. In: Baert, A.L., Ed., Encyclopedia of Diagnostic Imaging, 1st Edition, Springer, Berlin New York Heidelberg, 929-931.

[12] Martinez-Lavin, M., Vargas, A. and Rivera-Vinas, M. (2008) Hypertrophic Osteoarthropathy: A Palindrome with a Pathogenic Connotation. Current Opinion in Rheumatology, 20, 88-91. https://doi.org/10.1097/BOR.0b013e3282f14a5a

[13] Narayanan, S., Mohamed Gani, V.M. and Sundararaju, V. (2010) Primary Hypertrophic Osteoarthropathy with Hypertrophic Gastropathy. Journal of Clinical Rheumatology, 16, 190-192. https://doi.org/10.1097/RHU.0b013e3181e04d80 